tional level of the $X^{1} \Sigma^{+}$state. (An alternative explanation is that the new bands are due to an impurity which is formed with, and decays with, carbon monosulphide. However, we were unable to relate them to known spectra which might arise from contarnination of carbon disulphide.)

(4) With low pressures of carbon disulphide, $<0.05 \mathrm{~mm}$., the fluorescent spectrum of carbon monosulphide was excited with such intensity by the photolytic flash that the $v^{\prime}=0,1$ and 2 progressions could be recorded on Ilford $H P 3$ plate from one exposure with a slit width of $0.01 \mathrm{~mm}$. The band at $2589 \cdot 04 \AA$. referred to under (3) occurred only very weakly in emission. At the higher pressures of carbon disulphide that were required to produce a measurable over-population of the vibrational levels of carbon monosulphide, the fluorescence was completely quenched.

Thus we summarize the mechanism of vibrational excitation of carbon monosulphide as follows:

$$
\begin{aligned}
\mathrm{CS}_{2}+h \nu & \rightarrow \mathrm{CS}(?)+\mathrm{S}(?) \\
\mathrm{CS}(?) & \rightarrow \mathrm{CS} . X^{1} \Sigma^{+}(v=0)
\end{aligned}
$$

$\left.\mathrm{CS} . X^{1} \Sigma^{+}(v=0)+h v \rightarrow \operatorname{CS} . A^{1}\right\rceil(v=0$ and 1$)$

CS. $A^{1} I I(v=0$ and 1$)+M \rightarrow \rightarrow C S . X^{1} \Sigma^{+}(v=n)+M$

Department of Physical Chemistry,

$$
\begin{aligned}
& \text { A. B. Callear } \\
& \text { R. G. W. NorRish }
\end{aligned}
$$

University of Cambridge.

1 Baseo, N., Callear, A. B., and Norrish, R. G. W. (to be published). ${ }^{2}$ Martin, L. C., Proc. Roy. Soc., A, 89, 127 (1913).

3 Jevons, W., Proc. Roy. Soc., A, 117, 351 (1928).

-Crawford, F. H., and Shureliff, W. A., Phys. Rev., 45, 860 (1934).

"Kondratiev, v., C.R. Acad. sci. U.R.S.S., 20, 547 (1938).

- Porter, G., Proc. Roy. Soc., A, 200, 284 (1950).

7 Jones, A. V., J. Chem. Phys., 18, 1263 (1950).

\section{Influence of Moisture on the Spontaneous Heating of Coal}

RESEAHCH into the spontaneous hoating of coal has been concerned in the past with three well-defined problems. These are measurements of rates of oxidation of coal, measurements of heat produced by oxidation and thirdly the establishment and solution of differential equations describing rises in temperature in oxidizing coal. Recently, measurements of the heat of oxidation of coal in air of controlled humidity have been reported and also heats of desorption and adsorption of water vapour ${ }^{1,2}$.

In these experiments, sub-bituminous coals (Table 1) always showed a greater rate of loss of heat by evaporation of moisture in a dry air stream than their rate of heat generation by oxidation. This effect is illustrated in Fig. 1, which compares heat produced by oxidation of $4 \mathrm{gm}$. of coal with loss of heat by drying the same coal in a stream of dry nitrogen of $10 \mathrm{ml} . / \mathrm{min}$.

As a result of these exporiments it has recently been pointed out that transfer of heat by evaporation of moisture can be of over-riding importance in spontaneous heatings although this factor has previously been neglected ${ }^{3}$. For example, the linear transfer of

Table 1. Typical Anatysis of SUb-bituminous Coat, Ohai,

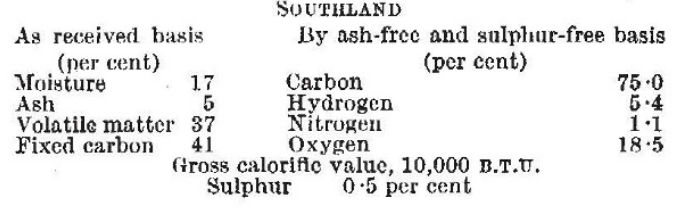

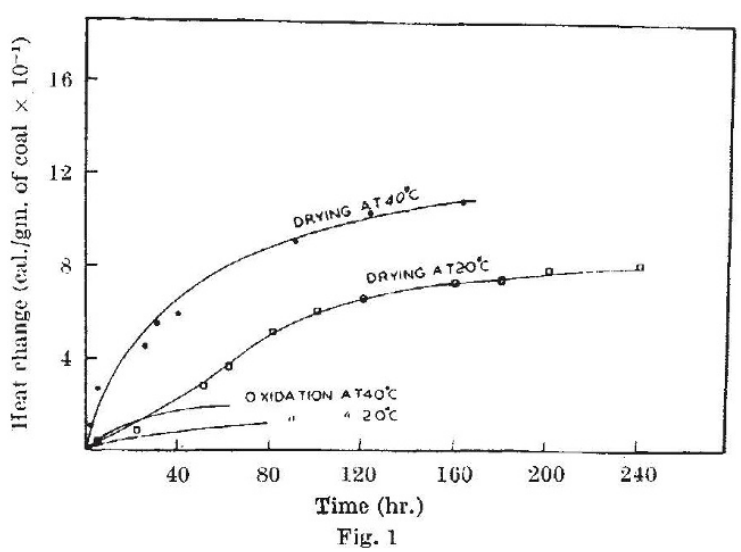

heat by conduction across a temperature gradient in crushed coal is about $3 \times 10^{-4} \mathrm{cal} / \mathrm{sec} . / \mathrm{cm} .^{2}$. If saturated air travels across this gradient and remains saturated but rises in temperature by $1 \mathrm{deg}$. C., then the increase in heat content of the air is $1 \times 10^{-2} \mathrm{cal} . / \mathrm{ml}$. of air and a flow as low as $0.03 \mathrm{ml} . / \mathrm{sec}$. across $1 \mathrm{sq}$. $\mathrm{cm}$. can be responsible for transfer of heat equal to that caused by conduction. Observations of spontaneous heating of coal heaps in New Zcaland mines confirm that air travelling through the heaps does remain saturated, though as yet rates of air flow have not been measured.

These results have led to an investigation of the behaviour of sub-bituminous coal the moisture of which has been removed in a vacuum of $0.05 \mathrm{~mm}$. mercury, at $105^{\circ} \mathrm{C}$. The coal was crushed to the sizes shown in Tablo 2 and cvacuated in less than $5 \mathrm{~min}$. to minimize oxidation.

Table 2. Size ANalysis of Coal USED in Spontaneous Ifeativg

$$
\begin{array}{ccc}
\text { LABORATORY EXPERIMENTS } \\
+1 / 10 \text { in. } & \text { B.S.S. } & 19 \text { per cent } \\
-1 / 10 \text { in. }+60 \text { mesh } & \text { B.S.S. } & 68 \text { per cent } \\
-60 \text { mesh } & \text { B.S.S. } & 13 \text { per cent } \\
& & 100 \text { per cent }
\end{array}
$$

It has been found that $3 \mathrm{kgm}$. of coal treated in this way will fire spontaneously in $30 \mathrm{~min}$. from a tomperature of $22^{\circ} \mathrm{C}$. when oxygen saturated with moisture at this temperature is passed through it at 1 litre/min. The coal is contained in a light aluminium foil cylinder, $12 \mathrm{~cm}$. in diameter and $24 \mathrm{~cm}$. high, with an open top. Air or oxygen enters the coal at a central point $2 \mathrm{~cm}$. from the bottom of the cylinder through a $3-\mathrm{mm}$. diameter glass tube pushed through the coal from its top surface. Saturated air at 1 litro/min. caused ignition in $12 \mathrm{hr}$. while dry oxygen ignited the coal in $12 \mathrm{hr}$. from a temperature of $18^{\circ} \mathrm{C}$.

Besides providing a striking demonstration of the importance of humidity in spontaneous heating, this experimental technique allows the spontaneous heat. ing of coals to be studied in the laboratory under conditions of heat transfer resembling those found in practice.

Coal Research Department,

J. В. Ктотт

School of Mines and Motallurgy,

University of Otago, Dunedin.

${ }^{2}$ Stott, J. B., J. Sci, Instr., 33, 68 (1956).

"Stott, J. B., Proc. Symp. Nature of Coal, Central Fuel Res. Inst., Tndia (1959).

${ }^{3}$ Stott, J. B., Proc. Mineral Conf., University of Otago, New Zealand (1956). 